\title{
A prospective study of the bacteriological profile and risk factors of infection after internal fixation of close fractures of long bones
}

\author{
Munin Borgohain, Debasish Bora*, Aswin Deepak Rajan
}

Department of Orthopaedics, Assam Medical College, Dibrugarh, Assam, India

Received: 02 November 2019

Revised: 06 December 2019

Accepted: 07 December 2019

\author{
*Correspondence: \\ Dr. Debasish Bora, \\ E-mail: debasish1932@gmail.com
}

Copyright: (C) the author(s), publisher and licensee Medip Academy. This is an open-access article distributed under the terms of the Creative Commons Attribution Non-Commercial License, which permits unrestricted non-commercial use, distribution, and reproduction in any medium, provided the original work is properly cited.

\begin{abstract}
Background: Infection in implant related procedures is dreaded due to difficulty in getting rid of it. Disappointment to patients and surgeons, drainage of health care and patients' resources is significant. Causes and risk factors are many related to host, environment and procedure. The bacteriological profile and antibiotic sensitivity have been changing trend with emerging resistance to many drugs.

Methods: A prospective observational study of 941 patients with operative fixation of long bone closed fractures. The details of the procedure, host characteristics were noted. Followed up in ward post operatively and after discharge to identify the cases of surgical site infection. Once identified they were evaluated with X-rays and lab parameters. Wound swabs or pus samples taken to find out the organisms and cultured to find the sensitivity.

Results: 116 patients (86 males and 30 females) developed SSI (incidence 12.42\%). Plate fixation (18.20\% infection rate), operative time $>1$ and half hours $(15.73 \%$ rate), fracture femur (16.66\% rate), ORIF (14.38\% rate), age $>60$ yrs were some of the risk factors. Co-morbidities like anaemia, diabetes, liver disease, lung disease, immunosuppressive drugs, hypertension, smoking, alcoholics had significant association with SSI. Staphylococcus aureus was the most common organism. Gram positive showed highest sensitivity to linezolid, vancomycin and tetracycline. Gram negative showed highest sensitivity to colistin and tigecycline.

Conclusions: Infection rate should be less than $1 \%$ and hence risk factors encompassing preoperative, intraoperative and postoperative period are to be controlled. Probably the first study from north east india showing the burden of orthopaedic SSI.
\end{abstract}

Keywords: Surgical site infection, Bateriological profile, Antibiotic sensitivity

\section{INTRODUCTION}

Absolutely clean OT is a myth. 5000-50000 skin particles are delivered from each physicians flora daily $20 \%$ contain live bacteria. ${ }^{1}$ Despite all hygienic measures, bacteria can be recovered from $90 \%$ of clean wounds at the time of closure. The source is endogenous $80 \%$ of the time. Thus, minor contamination is physiological. But in the orthopaedic scenario it is ill-fated due to the difficulty to get rid of it mostly because of the presence of implants. Surgical site infections (SSI) are the most common nosocomial infections in surgical patients and lead to prolonged hospital stay, readmissions to the hospital, and increased morbidity and mortality. ${ }^{2}$

Implant associated infections grow in biofilms predominantly mixed-species. Such bacteria adopt different characteristics from their planktonic counterparts. $^{3}$ They develop slowly, escape the immune response, trigger further inflammation, develop resistance to antibiotics and do not grow in cultures easily. ${ }^{4}$ After OT there is a race for the surface of implant between 
bacteria and the tissue which is accentuated by presence of immature biofilm matrices.

The host defence system eliminates most of the transient bacterial colonization. But situations like large inoculum exceeding threshold level, impaired host defence, traumatized tissue surfaces, presence of foreign body invites infection. SSI can have grave consequences. According to Whitehouse et al, SSIs following orthopedic surgery prolonged the total hospital stay by a median of 2 weeks, doubled re-hospitalization rates, increased healthcare costs by $300 \%$, and decreased overall physical and social functioning. ${ }^{5}$

We are heading into post antibiotic era. Since 2003 FDA has approved only 6 new antimicrobial agents. Organisms have been there since the beginning of civilization; new strains are identified but only few newer drugs have come which begin to despair due to resistance. Hence antibiotic stewardship is very necessary.

We did this study to assess the incidence and risk factors for SSI, classify the type of infection and find out the bacteriological profile and its sensitivity. Minority of SSI is inevitable but the first step to prevent and combat it will be to assess the burden of infection, its risk factors and the bugs responsible.

\section{METHODS}

This is a Hospital based prospective observational study from July 2018 to June 2019 conducted in department of Orthopaedics, Assam Medical College and Hospital after Ethical clearance was granted by Institutional Ethics Committee (H).

Patients with internal fixation of closed fractures of long bones, deformity correction of long bones with internal fixation were included. Open fractures, Pathological fractures, external fixation for closed fractures, patients having co-existing osteo-articular infections were excluded. Also, spinal instrumentation, non-long bone fractures, arthroplasty and arthroscopy procedures and patients not giving consent were excluded.

Patient particulars and OT parameters are noted for all patients in a preformed performa. Comorbidities like anaemia, hypertension, smoking history, alcohol intake, liver disease, lung disease, immunosuppressive drug use were noted. Operative method, OT duration, hospital stay-pre operative and post operative, use of drains, class of wound were also noted in details. Post operatively patients were screened during hospital stay for infection and then followed up on 10th day after discharge and monthly thereafter. If any signs of infection were evident in between they were asked to contact via phone or attend hospital.

A surgical site infection was defined according to centre of disease control's (CDC) criteria. $^{6}$
First criterion was purulent drainage, with or without laboratory confirmation from the incision site or any discharging sinus. Second criterion was organisms isolated from an aseptically obtained culture of fluid or tissue from the incision site or any discharging sinus. And third criterion was at least one of the following signs or symptoms of infection: pain or tenderness, localised swelling, redness or heat.

Infection was classified as superficial which involved only the skin or subcutaneous tissue of the incision. Deep infection was one which involves the bones that occur when the infectious process invades tissues deep to the muscular fascia. Florid infection was one when there are systemic signs of infection, abscess collection, cellulitis or discharging pus from the sinus tract. Low grade infection was one when persistent watery sinus track discharge along with radiological evidence of osteomyelitis and loosening of implant is present. ${ }^{7}$ It was classified as early (less than 2 weeks), delayed (2 to 10 weeks), and late onset (more than 10 weeks). Prophylactic as well as therapeutic i.v. antibiotics were administered routinely as per decision of the antibiotic protocol of the college and tailored according to culture and sensitivity report in case of SSI.

The statistical analysis was performed using the computer program Statistical Package for Sciences (SPSS for windows, version 20.0 Chicago, SPSS Inc.) and Microsoft Excel 2010. Results on continuous measurements are presented as mean $\pm \mathrm{SD}$ and compared using student $\mathrm{t}$ test. Discrete data are expressed as number $(\%)$ and are analysed using chi square test. For all analysis statistical significance was fixed at 5\% level $(\mathrm{p}<0.05)$.

\section{RESULTS}

Out of the total 941 cases, 116 cases developed SSI, overall incidence being $12.32 \%$ (Figure 1). The occurrence of SSI was found to be high in older individuals, highest being for patients above $60(15.18 \%$ infection rate). Majority of infection (42 cases) developed with OT time 90 to 120 minutes ( $15.73 \%$ rate). Plate fixations were most commonly infected with $18.20 \%$ infection rate. Femur with 46 (16.66\% infection rate) cases of SSI was also the most commonly infected bone. Average mean pre-operative hospital stay was 8.20 44.50 days the mean total hospital stay was $15.11 \pm 5.57$ days in SSI cases. Infection occurred more in open reduction of fractures $14.56 \%$ compared to closed reduction $8.36 \%$ (Table 1).

Patients with anaemia had infection rate of $15.45 \%$, hypoalbuminemia $16.84 \%$, diabetic $17.24 \%$, hypertension $7.37 \%$, liver disease $12 \%$, COPD $7.27 \%$, smokers $8.76 \%$, alcoholics $9.39 \%$ and immunosuppressive or steroid users $4.87 \%$ (Table 2).

Staphylococcus aureus was isolated from $33.03 \%$ of the cases developing SSI. MRSA were 12 cases (10.34\%), 
Pseudomonas aeruginosa 25.89\%, Klebsiella $22.41 \%$, Escherichia coli 7.14\%, Proteus 6.34\%, Citrobacter $6.34 \%$, Acinetobacter $3.3 \%$ and Enterobacter was found in $1.72 \%$ of the cases. No organisms in $14(12.06 \%)$ cases and $13(11.20 \%)$ cases showed mixed growth (Table 3).

The early, delayed and late onset infections occurred in 46 (39.65\%), 39 (33.63\%) and 31 (26.72\%) patients respectively. Superficial infection occurred in 71 cases $(61.20 \%)$ and deep infection occurred in 45 cases $(38.79 \%)$ (Table 4).

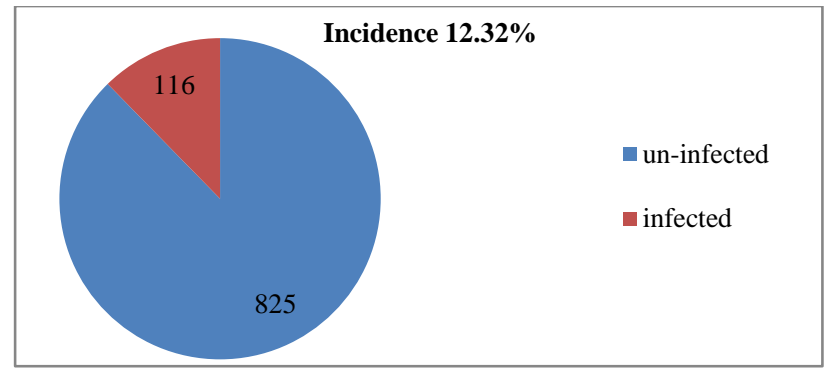

Figure 1: Overall incidence infection.

Table 1: Risk factors.

\begin{tabular}{|c|c|c|c|}
\hline \multirow{2}{*}{ Factor } & Total & Infected & \multirow{2}{*}{ P value } \\
\hline & $\mathbf{N}(\%)$ & $\mathbf{N}(\%)$ & \\
\hline \multicolumn{4}{|l|}{ Age (in years) } \\
\hline $0-20$ & 167 (17.74) & $10(5.98)$ & \multirow{4}{*}{0.0489} \\
\hline $21-40$ & $322(34.21)$ & $42(13.04)$ & \\
\hline $41-60$ & $373(39.63)$ & $52(13.945)$ & \\
\hline$>60$ & $79(8.39)$ & $12(15.18)$ & \\
\hline \multicolumn{4}{|l|}{ Sex } \\
\hline Male & $616(65.46)$ & $86(13.96)$ & \multirow{2}{*}{0.0358} \\
\hline Female & $325(34.54)$ & $30(9.23)$ & \\
\hline \multicolumn{4}{|l|}{ Bone } \\
\hline Femur & $276(29.33)$ & $46(16.66)$ & \\
\hline Tibia & $192(20.40)$ & $25(13.02)$ & \\
\hline Humerus & $125(13.28)$ & $12(9.60)$ & \\
\hline Forearm & $172(18.27)$ & $22(12.79)$ & \\
\hline Clavicle & $93(9.88)$ & $5(5.37)$ & \\
\hline Meta-tarsals & $44(4.68)$ & $3(6.81)$ & \\
\hline Meta-carpals & $39(4.14)$ & $3(7.69)$ & \\
\hline Upper limb & $429(45.58)$ & $42(9.79)$ & \multirow{2}{*}{0.0302} \\
\hline Lower limb & $512(54.42)$ & $74(14.45)$ & \\
\hline \multicolumn{4}{|l|}{ Implant } \\
\hline Plate & $474(50.37)$ & $73(18.20)$ & \multirow{3}{*}{0.0135} \\
\hline IM nail & $241(25.61)$ & $24(11.05)$ & \\
\hline $\mathrm{K}$ wires $\pm \mathrm{SS}$ wires and screws & $226(24.01)$ & $19(9.31)$ & \\
\hline \multicolumn{4}{|l|}{ Duration (min) } \\
\hline $30-60$ & $215(22.84)$ & $21(9.76)$ & \multirow{5}{*}{0.0015} \\
\hline $60-90$ & $369(39.21)$ & $41(11.11)$ & \\
\hline $90-120$ & $267(28.38)$ & $42(15.73)$ & \\
\hline$>120$ & $90(9.57)$ & $12(13.33)$ & \\
\hline Mean & & $78.09 \pm 26.63$ & \\
\hline \multicolumn{4}{|l|}{ Method } \\
\hline ORIF & $604(0.6)$ & $88(14.56)$ & \multirow{2}{*}{0.005} \\
\hline CRIF & $337(0.35)$ & $28(8.30)$ & \\
\hline \multicolumn{4}{|l|}{ Preoperative stay } \\
\hline$<1$ week (<7 days $)$ & $469(49.84)$ & $51(10.87)$ & \multirow{2}{*}{0.0012} \\
\hline 1-2 week (7-14 days) & $294(31.24)$ & $41(13.94)$ & \\
\hline$>2$ week (>14 days) & $178(18.92)$ & $24(13.48)$ & \\
\hline \multicolumn{4}{|l|}{ Total stay } \\
\hline 1-2 week (7-14 days) & $438(46.52)$ & $48(10.95)$ & \multirow{3}{*}{$<0.0001$} \\
\hline 2-3 week (14-21 days) & $322(34.21)$ & $43(13.35)$ & \\
\hline$>3$ week (>21 days) & $181(19.23)$ & $25(13.81)$ & \\
\hline Total & $941(100)$ & $116(12.42)$ & \\
\hline
\end{tabular}


Table 2: Co-morbid factors.

\begin{tabular}{|llll|}
\hline Factors & No. of cases & No. of cases with SSI & P value \\
\hline Anaemia & $349(37.08)$ & $53(15.45)$ & 0.040535 \\
\hline Hypo-albuminemia & $190(20.190$ & $32(16.84)$ & 0.034094 \\
\hline Diabetes & $174(18.49)$ & $30(17.24)$ & 0.028961 \\
\hline Hypertension & $266(28.26)$ & $18(7.37)$ & 0.001126 \\
\hline Liver disease & $75(7.97)$ & $9(12.00)$ & 0.928383 \\
\hline COPD (lung disease) & $55(5.84)$ & $4(7.27)$ & 0.239951 \\
\hline Smoker & $308(32.73)$ & $27(8.76)$ & 0.020458 \\
\hline Alcoholic & $362(38.46)$ & $34(9.39)$ & 0.030349 \\
\hline Immunosupressive or steroid therapy & $41(4.31)$ & $2(4.87)$ & 0.137919 \\
\hline No co-morbidity & $333(35.38)$ & $12(3.60)$ & - \\
\hline
\end{tabular}

Table 3: Bacteriological profile.

\begin{tabular}{|lll|}
\hline Organisms isolated & Number $(\mathbf{n}=\mathbf{1 1 6})$ & Percentage (\%) \\
\hline Staphylococcus aureus (coagulase positive) & 29 & 25.89 \\
\hline Staphylococcus aureus (coagulase negative) & 8 & 7.14 \\
\hline Escherichia coli & 8 & 7.14 \\
\hline Pseudomonas aeruginosa & 29 & 25.89 \\
\hline Klebsiella species & 26 & 22.41 \\
\hline Proteus vulgaris & 7 & 6.34 \\
\hline Citrobacter & 7 & 6.34 \\
\hline Acinetobacter species & 2 & 3.3 \\
\hline Enterbacter & 3 & 1.72 \\
\hline No organisms & 14 & 12.06 \\
\hline Mixed growth & 13 & 11.20 \\
\hline
\end{tabular}

Table 4: Classification of SSI.

\begin{tabular}{|lll|}
\hline Presentation & SSI cases & Percentage (\%) \\
\hline Early & 46 & 39.65 \\
\hline Delayed & 39 & 33.63 \\
\hline Late & 31 & 26.72 \\
\hline Depth superficial & 71 & 61.21 \\
\hline Deep & 45 & 38.79 \\
\hline Nature: low grade & 74 & 63.79 \\
\hline Florid grade & 42 & 36.21 \\
\hline
\end{tabular}

Table 5: Antibiotic sensitivity pattern.

\begin{tabular}{|lllllllll|}
\hline \multirow{2}{*}{ Antibiotics } & S. aureus & \multicolumn{3}{c}{ CONS } & \multicolumn{2}{c|}{ Pseudomonas } & \multicolumn{2}{l|}{ Klebsiella } \\
\hline Penicillin & S & R & S & R & S & R & S & R \\
\hline Ceftriaxone & 2 & 27 & 1 & 7 & NA & NA & NA & NA \\
\hline Vancomycin & 17 & 12 & 3 & 5 & 16 & 13 & 12 & 14 \\
\hline Linezolid & 28 & 1 & 6 & 0 & NA & NA & NA & NA \\
\hline Ciprofloxacin & 26 & 3 & 7 & 1 & NA & NA & NA & NA \\
\hline Clindamycin & 15 & 14 & 2 & 6 & 13 & 16 & 12 & 14 \\
\hline Piperacillin tazobactum & 21 & 8 & 6 & 2 & NA & NA & NA & NA \\
\hline Meropenem & NA & NA & NA & NA & 14 & 15 & 14 & 12 \\
\hline Imipenem & NA & NA & NA & NA & 21 & 8 & 19 & 7 \\
\hline Colistin & NA & NA & NA & NA & 23 & 6 & 21 & 5 \\
\hline Tigecycline & NA & NA & NA & NA & 22 & 0 & 21 & 0 \\
\hline Levofloxacin & NA & NA & NA & NA & 24 & 0 & 19 & 0 \\
\hline
\end{tabular}




\begin{tabular}{|lllllllll|}
\hline \multirow{2}{*}{ Antibiotics } & S. aureus & & CONS & \multicolumn{2}{l|}{ Pseudomonas } & \multicolumn{2}{l|}{ Klebsiella } \\
\hline Tetracycline & S & R & S & R & S & R & S & R \\
\hline Teicoplanin & 27 & 2 & 6 & 0 & NA & NA & NA & NA \\
\hline Amikacin & 26 & 3 & 6 & 2 & NA & NA & NA & NA \\
\hline Mupirocin & NA & NA & NA & NA & 8 & 21 & 7 & 19 \\
\hline Cotrimoxazole & 20 & 9 & 5 & 3 & NA & NA & Na & NA \\
\hline Minocycline & 18 & 11 & 5 & 2 & NA & NA & NA & NA \\
\hline Ertapenem & NA & NA & NA & NA & 23 & 6 & 21 & 5 \\
\hline
\end{tabular}

$\mathrm{NA}=$ not available, $\mathrm{S}=$ sensitive, $\mathrm{R}=$ resistant.

This study shows that most of the staphylococci aureus were resistant to penicillin, and most of them were sensitive to linezolid, tetracycine and vancomycin. Pseudomonas showed good sensitivity towards colistin, tigecycline and mostly resistance to cephalosporins, amikacin and gentamycin. Imipenem, meropenem and piperacillin or tazobactum showed moderate sensitivity. Klebsiella was found to show good sensitivity to colistin, tigecycline, minocycline and levofloxacin. Meropenem and imepenem showed moderate sensitivity. Klebsiella species showed an antibiogram pattern almost similar to Pseudomonas (Table 5).

\section{DISCUSSION}

In our study also, highest percentage of infected cases were in the age group $>60$ years which was $15.18 \%$. Khosravi et al, Jain et al, Khan et al, Tago et al and Dhillon et al also reported advanced age as a major risk factor. $^{8-12}$ It can be due to multiple factors like malnutrition, mal-absorption, low healing rate, decreased immunity, increased catabolism etc.

Rate of infection among male patients was $13.96 \%$ and among female patients was $9.23 \%$. Razavi et al, Chang et al, Kumar et al, Keswani et al and Khosravi et al found male cases more commonly infected..$^{8,13-16}$ However, the studies by Raf, Lidgren et al showed either sex can develop infection equally. ${ }^{17,18}$ Pergola et al has shown that testosterone suppresses phospholipase D. ${ }^{19}$ There are sexual differences in leukotriene biosynthesis in human monocytes, the central cells for immunity. ${ }^{20}$

Awan et al, Jain et al found anaemia to be an important risk factor. ${ }^{9,21}$ Khosravi et al, Nazri et al and Khan et al reported smoking to be an important risk factor. ${ }^{8,10,22}$ Ozkalkanli et al, Bohl et al and Grammatico et al stated high risks of malnutrition and hypoalbuminemia with SSI. ${ }^{23-25}$ Cavanaugh et al and Jain et al stated the high risk associated with alcoholism and SSI. ${ }^{26,27}$ A systemic review on the management of SSI was adopted by AAOS (American Academy of Orthopaedics Surgeons Board of Directors on June 9, 2018) where significant association between immunosuppressive agents, hypertension, liver disease on surgical site infections was found. Risk factors loweres host resistance to infection and hence are more infected. $^{28}$
The incidence of SSI in our study was recorded to be $12.32 \%$. The accepted standard for postoperative infection should be less than $1 \%$. Various authors have reported various rates of post-operative infection. It is reported from $0.5-5 \%$ by $\mathrm{Raf}$ et al, roles and $3.6 \%$ by Lidgren et al. ${ }^{8,18,29}$ It was $3.97 \%$ as reported by Jamali et al, $5 \%$ by Tago et al, $5.76 \%$ by Khan et al, $7.8 \%$ by Iqbal et al and $8.264 \%$ by Ibtesam et al. ${ }^{10,11,30-32}$ However, significantly higher infection rate of $22.58 \%$ was reported by Jain et al. ${ }^{9}$ The difference in incidence of postoperative infection in different studies may be related to difference in inclusion criteria, surgical set ups and facilities available.

We found, patients with $>1$ and half hour OT time had increase rate of infection. Patel et al, Sawyer et al and Chowdhury et al found increased operative time to be an important risk factor of SSI. ${ }^{33-35}$ Increased damage to the tissues due to prolonged handling, weaning serum antibiotic level, more exposure to the surrounding environment are some other attributable factors.

Jain et al and Kumar et al reported increased preoperative hospital stays to be an important risk factor of SSI. Similar association is seen in our study.,36 Longer preoperative hospital stay leads to increased opportunities for bacterial colonization. It also leads to development of antimicrobial resistant microorganisms and affects patientss susceptibility to fight infection by lowering host immunity.

$88(14.56 \%)$ ORIF cases and $28(8.30 \%)$ cases of CRIF method developed SSI. Khan et al, Lidgren et al, Kumar et al and Jain et al also reported increased incidence of SSI with open reduction procedures. ${ }^{9,10,18,36}$ Open reduction invited more chances of bacterial inoculation and hence more risk.

In our study, S. aureus was isolated from $33 \%$ of the cases developing SSI. 12 among them were MRSA. Pseudomonas aeruginosa 25\%, Klebsiella 22\%, E. coli $7 \%$, Proteus $6 \%$, Citrobacter 6\%, Acinetobacter 3\% and Enterobacter was found in $2 \%$ of the cases. No organisms in 14 cases (5\%). Jain et al (39.27\%), Khan et al $(50 \%)$, Lidgren et al (67\%) and Tago et al $(67.30 \%)$ in various studies reported Staphylococci as the most prevalent organism and Mousa et al reported 
$P$. aeruginosa and Jain et al found $E$. coli as the significant isolated organism. ${ }^{9-11,18,37}$

Overall, S. aureus remains the commonest organism in infection related to the bone. Contributing factors to this include its predilection for this tissue, presence of the surface receptor for the human intracellular proteins and the Staphylococcal toxins. S. aureus adheres to such hosttissue ligands via genetically defined microbial surface proteins, commonly referred to as - microbial surface components recognizing adhesive matrix molecules\| (MSCRAMM). The most important MSCRAMMs include FnbpA and FnbpB, which bind to fibronectin; clumping factor, which binds to fibrinogen and collagen adhesins, which binds to collagen. It commonly colonises the skin and the nares, hence a ready source of infection. ${ }^{38}$

In our study, the isolated Staphylococci were found to be sensitive to linezolid, vancomycin $(100 \%)$, tetracycline (94\%), mupirocin (83\%), clindamycin $(73 \%)$ of the cases. Most staphylococci isolates were found to be resistant to penicillin and cephalosporins. Among the gram-negative bacteria tigecycline $(100 \%)$, colistin $(100 \%)$ were the most sensitive. Other effective antibiotics with their sensitivity were meropenem (72\%), levofloxacin $(58 \%)$, pipercillin and tazobactum (52\%), imipenem (88\%) and amikacin $(29 \%)$. Tunney et al reported vancomycin and ciprofloxacin as most effective antibiotics against isolated bacteria. ${ }^{39}$ Khosravi et al and Kumar et al found that staph showed high sensitivity to vancomycin and linezolid. ${ }^{8,36}$ Thool et al found less sensitivity of linezolid. ${ }^{40}$ Bubbar in their study also found that antimicrobial profile of gram positive isolates revealed maximum sensitivity to vancomycin, teicoplanin and linezolid, whereas among gram negative isolates meropenem, piperacillintazobactam, and amikacin were found to be most sensitive. ${ }^{41}$

In our study early, delayed and late onset infections occurred in 46 (39.65\%), 39(33.62\%) and 31(26.72\%) patients respectively. Khan et al and Thool et al reported equal numbers of early, delayed and late infection. ${ }^{10,40}$ Raf et al, Lidgren et al found more of delayed infection. ${ }^{17,18}$ Jain et al found more of early infection followed by late and late infections. ${ }^{9}$

We found 71 cases $(61.20 \%)$ Superficial infection and 45 cases $(38.79 \%)$ deep infection. Khan et al Awan et al, Jain et al reported more superficial infection rate. ${ }^{9,10,21}$ Raf et al found more of deep infections. ${ }^{17}$

In our study $73(18.20 \%)$ plate fixation developed SSI. Our results were similar to the one by Nazri et al and Khan et al who found more infection with plates. ${ }^{22}$ Maybe it was due to the softer tissue exposure and compromise of sterility with plate fixation which generally needed an open procedure.
Femur $(n=46,16.66 \%)$ was also the most commonly infected bone and more lower limb fractures 74 (14.45\%) developed SSI. Similar results were reported by Khosravi et al, Kumar et al, Nazri et al and Raahave found more post-operative infection rate in the lower extremity. ${ }^{8,22,36,41}$ Lidgren et al found higher infection rates after operation in the hip region. ${ }^{18}$ Bubbar compared different regions but found no difference. ${ }^{42}$

\section{CONCLUSION}

Host tissue and bacteria races for the implant surface the day an implant is put. The race is won by the bacteria when there are risk factors associated. Once inoculation occurs, the organisms form a biofilm layer over the implant leading to implant associated infections which are quite different from the Surgical site infection as described by CDC. The early, delayed and late classification has significant impact on outcome. Delayed and late infection may have less features but grave impact on fixation and outcome. We found a very high incidence of infection in our study. Ideally it should be less than $1 \%$. Our aim should be to prevent and minimize the modifiable risk factors like nature of operative procedure, length of surgery, duration of hospital stay, glycemic levels etc. Other factors like age, sex etc. cannot be modified. A lot of antibiotics are showing resistance. Strict adherence to antibiotic protocol and antibiotic stewardship should be the main objective. High end antibiotics and reserved antibiotics should be used with caution. There should be responsible planning and management of resources. Drugs that are necessary should be used, de-esclated when possible and more is not always better. Sub-optimal dose and prolonged dose leads to resistance. Infection has very significant effect on the functional outcome. More research, better definition and responsible decision making are need of the hour.

\section{ACKNOWLEDGEMENTS}

Very grateful to Department of Microbiology Assam Medical College, Dibrugarh for help in this research.

Funding: No funding sources

Conflict of interest: None declared

Ethical approval: The study was approved by the institutional ethics committee

\section{REFERENCES}

1. Oakes JA, Wood AJJ. Infections in surgery. N Engl J. 1986;315:1129-38.

2. Van Kasteren ME, Mannien J, Kullberg BJ, de Boer AS, Nagelkerke NJ, Ridderhof M, et al. Quality improvement of surgical prophylaxis in Dutch hospitals: evaluation of a multi-site intervention by time series analysis. J Antimicrob Chemother. 2005;56(6):1094-102. 
3. Stoodley P, Sauer K, Davies DG, Costerton JW. Biofilms as complex differentiated communities. Annu Rev Microbiol. 2002;56:187-209.

4. Costerton JW, Stewart PS, Greenberg EP. Bacterial biofilms: A common cause of persistent infections. Science. 1999;284:1318-22.

5. Whitehouse JD, Friedman ND, Kirkland KB, Richardson WJ, Sexton DJ. The impact of surgical-site infections following orthopedic surgery at a community hospital and a university hospital: Adverse quality of life, excess length of stay, and extra cost. Infect Control Hosp Epidemiol. 2002;23:183-9.

6. Horan TC, Gaynes R, Martone WJ, Jarvis WR, Emori TG. CDC definitions of nosocomial surgical site infections, 1992: a modification of CDC definitions of surgical wound infections. Infect Control Hosp Epidemiol. 1992;13:606-8.

7. Willenegger $\mathrm{H}$, Roth $\mathrm{B}$. Treatment tactics and late results in early infectionfollowing osteosynthesis. Unfallchirurgie. 1986;12:241-6.

8. Khosravi A, Ahmadi F, Salmanzade S, Dashtbozorg A, Montazeri EA, et al. Study of bacteria isolated from Orthopaedic implant infections and their antimicrobial susceptibility pattern. Res J Microbiol. 2009;4(4):158-63.

9. Jain BK, Banerjee M. Surgical site infections and its risk factors in orthopaedics: a prospective study in teaching hospital of central India. Int $\mathbf{J}$ Res Med. 2013;2(1):110-3.

10. Khan MS, ur Rehman S, Ali MA, Sultan B, Sultan S. Infection in orthopaedic implant surgery, its risk Factors and outcome. J Ayub Med Coll Abbottabad. 2008;20(1):23-5.

11. Tago IA, Asfhaq K, Gill P, Memon K, Kumar N Mahboob G. Post-operative infection in clean cases with the use of implant and their management. J Pakorthopassoc. 2007;19(2):46-56.

12. Dhillon KS, Kok CS. The incidence of post operative wound infection in orthopaedic surgery. Med J Malayasia. 1995;50(3):237-40.

13. Razavi SM, Ibrahimpoor M, Kashani AS, Jafarian A. Surgical site infections: incidence and risk factors at an Iranian teaching hospital. BMC surgery. 2005;5(1):2.

14. Kumar A, Rai A. Prevalence of surgical site infection in general surgery in a tertiary care centre in India. Int Surg J. 2017;4:3101-6.

15. Chang WT, Lee KT, Chuang SC, Wang SN, Kuo $\mathrm{KK}$, Chen JS, et al. The impact of prophylactic antibiotics on postoperative infection complication in elective surgery: a prospective randomized study. Am J Surg. 2006;191(6):721-5.

16. Keswani S, Akhtar M, Saxena D, Deshpande G. Predictive factors of surgical site infections. Int Surg J. 2018;5:971-4.

17. Raf L. Staphylococcal wound infection complicating orthopaedic operations. Acta Orthop Scand. 1964;34:289-98.
18. Lidgren L, Lindberg L. Post-operative wound infections in clean orthopaedic surgery: Review of a 5-year material. Acta Orthop Scand. 1974;45(2):161-9.

19. Pergola C, Rogge A, Dodt G. Testosterone suppresses phospholipase $\mathrm{D}$, causing sex differences in leukotriene biosynthesis in human monocytes. FASEB J. 2011;25:3377-87.

20. Rønø B, Engelholm LH, Lund LR, Hald A. Gender affects skin wound healing in plasminogen deficient mice. PLoS One. 2013;8:e59942.

21. Awan MS, Dhari FJ, Laghari AA, Bilal F, Khaskheli NM. Surgical Site infection in Elective Surgery. J Surg Pakistan. 2011;16(1):33-7.

22. Nazri MY, Halim YA. Outcome of Infection Following Internal Fixation of Closed Fractures. Med J Malaysia. 2004;59(5).

23. Ozkalkanli MY, Ozkalkanli DT, Katircioglu K, Savaci S. Comparison of tools for nutrition assessment and screening for predicting the development of complications in orthopedic surgery. Nutr Clin Pract. 2009;24(2):274-80.

24. Bohl DD, Shen MR, Mayo BC, Massel DH, Long WW, Modi KD, et al. Malnutrition Predicts Infectious and Wound Complications Following Posterior Lumbar Spinal Fusion. Spine (Phila.Pa.1976.). 2016;21:1693-9.

25. Grammatico-Guillon L, Baron S, Rosset P, Gaborit C, Bernard L, Rusch E, et al. Surgical Site Infection After Primary Hip and Knee Arthroplasty: A Cohort Study Using a Hospital Database. Infect. Control Hosp Epidemiol. 2015;10:1198-207.

26. Jain RK, Shukla R, Singh P, Kumar R. Epidemiology and risk factors for surgical site infections in patients requiring orthopedic surgery. Eur J Orthop Surg Traumatol. 2015;2:251-4.

27. Cavanaugh PK, Chen AF, Rasouli MR, Post ZD, Orozco FR, Ong AC. Complications and Mortality in Chronic Renal Failure Patients Undergoing Total Joint Arthroplasty: A Comparison Between Dialysis and Renal Transplant Patients. J Arthroplasty. 2016;31(2):465-72.

28. Shaffer WO, Cummins D, Murray J, Schulte D. Systematic literature review on the management of surgical site infections- Adopted by the American Academy of Orthopaedic Surgeons Board of Directors. 2018: 1-54.

29. Roles NC. Infection in total prosthetic replacement of the hip and knee joints. Proc. rog. SOC. Med. 1971;64(6):636-8.

30. Jamali AR, Mehboob G, Majid A, Bhatti A, Minhas S, Akhtar R, et al. Postoperative wound infections in Orthopaedic surgery. J Coll Physicians Surg Pak. 2001;11:746-9.

31. Iqbal MZ, Chima TA, Sabir MR. Rate of postoperative infection in clean orthopaedic cases. J Pak Orthop Assoc. 2001;13:121-4.

32. Ibtesam KA, Ehssan AB. Three months study of orthopaedic surgical site infections in an Egyptian 
University hospital. Int $\mathrm{J}$ Infect Control. 2010;6(1):25-7.

33. Patel SM, Patel MH, Patel SD, Soni ST, Kinariwala DM, Vegad MM. Surgical site infections: Incidence and risk factors in a tertiary care hospital, western India. National J Community Med. 2012;3(2):193-6.

34. Sawyer RG, Pruett TL. Wound infections. Surg Clin North Am. 1994;74:519-36.

35. Chowdhury MAM, Ferdous A. Identification of risk factors for post- surgical wound infections in elective operations: A multivariate statistical analysis. 2010;5:1.111.11.

36. Kumar S, Sengupta M, Hada V, Sarkar S, Bhatta R, Gupta MS. Early post-operative wound infection in patients undergoing orthopaedic surgery with implant. Int J Sci Stud. 2017;5(8):44-8.

37. Mousa HA. Infection following orthopaedic implants and bone surgery. East Mediterr Health J. 2001;7:738-43

38. Darouiche RO, Landon GC, Patti GM, Nguyen LL, Fernau RC, McDevitt D, et al. Role of Staphylococcus aureus surface adhesions in orthopaedic device infections. J Med Microbiol. 1997;46:75-9.
39. Tunney MM, Ramage G, Patrick S, Nixon JR, Murphy PG, Gorman SP. Antimicrobial susceptibility of bacteria isolated from orthopaedic implants following revision hip surgery. Antimicrob Agents Chemother. 1998;42(11):3002-5.

40. Thool VU, Bhoosreddy GL, Wadher BJ. Detection of resistance to linezolid in staphylococcus aureus infecting orthopedic patients. Indian J Pathol Microbiol. 2012;55:361-4.

41. Raahave D. Penicillin concentrations in abdominal operation wounds after intravenous administration. Scand J Gastroenterol. 1975;10(5):551-5.

42. Bubbar VK. The Intention-to-Treat Principle: A Primer for the Orthopaedic Surgeon. J Bone Joint Surg (Am). 2006;88(9):2097.

Cite this article as: Borgohain M, Bora D, Rajan AD. A prospective study of the bacteriological profile and risk factors of infection after internal fixation of close fractures of long bones. Int J Res Orthop 2020;6:345-52. 